\title{
Digital inequalities: a review of contributing factors and measures for crossing the divide
}

\author{
Eli Hustad ${ }^{1[0000-0002-1150-1850]}$, June L. Hansen ${ }^{1}$, \\ Andreas Skaiaa ${ }^{1}$ and Polyxeni Vassilakopoulou ${ }^{1[0000-0002-5947-4070]}$ \\ ${ }^{1}$ University of Agder, Kristiansand, Norway \\ \{eli.hustad, junelh17, oands17, polyxenv\}@uia.no
}

\begin{abstract}
This literature review focuses on the digital divide in contemporary technologically and economically advanced societies. Prior research shows that the digital divide entails more than physical accessibility and points to issues of technology acceptance and actual use. Recurring digital divide factors outside socioeconomic characteristics were identified in the articles reviewed. These factors relate to personality traits, motivation and digital skills. The factors can be used as the basis for a personality model for understanding acceptance and use of technology complementing models related to economic and social resources. Furthermore, measures for crossing the divide are traced in the literature and organized in three key intervention domains related to policy, training and design. The findings of this review can be a foundation for further research orienting researchers within the domain.
\end{abstract}

Keywords: Digital divide, ICT access, ICT acceptance, digitalization, motivation, personality, skills

\section{Introduction}

Citizens are increasingly expected to participate online using information and communications technologies (ICT) in order to utilize digitalized services. The continuous effort to digitalize society poses a challenge for individuals who are not fully capable of using the digital tools necessary for accessing online services. This can have severe consequences for citizen groups who may feel partially excluded or completely left out of society because of their inability to adapt to digitalization.

Phenomena of digital inequalities are referred to with the term digital divide signifying the gap between individuals, households, businesses or geographic areas regarding opportunities to access and use ICTs and the Internet for a variety of activities $[1,2]$. According to Van Dijk [3], digital inequality concerns have shifted from unequal motivation and physical access to inequalities of skills and usage. In terms of physical access, the divide seems to be closing in the developed countries, but inequalities in digital skills and application use persist. In the past, the digital divide literature was mostly driven by policy-oriented reports that focused on access. Scientific research in the domain foregrounded the multifaceted nature of digital inequality beyond access; 
researchers pointed to issues related to knowledge, economic and social resources, attributes of technology such as performance and reliability, and utility realization [46]. Investigations go mostly beyond questions of access (the so-called "first-level digital divide") to examining factors that affect people's ability to make good use of digital resources.

Understanding how digital inequalities emerge in settings that are advanced in terms of technological infrastructure and economy and finding ways to address such inequalities is today more important than ever. The digital divide is a serious threat to civil society in an era where public services go digital. For instance, daily activities such as paying bills, filling in application forms, filing tax returns, are all expected to be carried out electronically There are high expectations for active citizens' role based on online services $[7,8]$; hence, we need to be constantly in the lookout for digital inequalities ensuring fairness and inclusiveness.

Our study identifies, analyses, and integrates a critical mass of recent research on the digital divide focused on places where the technological infrastructures and economies are advanced. To ensure a robust result, we performed a systematic literature review [9] guided by the following question: What are the key research findings of the factors that contribute to the digital divide in contemporary technologically and economically advanced settings? Our contribution is threefold. First, we identify recurring digital divide factors and we map these factors to different groups of people that are threatened by digital inequality in modern societies. Second, we present different measures proposed in the literature and organize them in three key intervention domains. Finally, as a third contribution, we identify areas for future research providing a foundation for researchers to aim to engage with the domain.

The remainder of the paper is organized as follows. First, we present the method used for selecting and analyzing the articles for this review. Then we offer a synthesis of our findings related to digital divide factors and related measures and present them in a concise concept matrix. We continue by discussing the implications for further research and we end with overall concluding remarks.

\section{Research Approach}

The systematic literature review was performed by following the process proposed by Kitchenham [9]. This structured approach encompasses three main steps: a) planning the review, where a detailed protocol containing specific search terms and inclusion/exclusion criteria is developed, b) conducting the review, where the selection, appraisal and synthesis of prior published research is performed and c) reporting the review, where the write-up is prepared. We used these steps as our methodological framework. In addition, we utilized principles suggested by Webster and Watson [10] for the analysis of the articles included in the review. Following these principles, we identified key concepts and created a concept-centric matrix that provides an overview of the literature reviewed.

To identify and select research articles to be reviewed, a set of search terms and a set of inclusion/exclusion criteria were used. The search terms consisted of the words 
Digital and Divide. We decided to search for any combination of these two words in the abstract, title and keywords of published articles instead of searching for the string "Digital Divide" which can be too restrictive. Moreover, we conducted backward and forward searches to review relevant citations. The primary search was performed in Scopus and we used Google Scholar for our backward and forward searches.

Inclusion and exclusion criteria were established to reduce selection bias, guarantee the quality of the papers selected and increase the validity of our review. Peer-reviewed, empirical papers, written in English, published within information systems research between 2010 and 2018 were included. Conceptual papers that lacked empirical evidence, reviews, and papers focusing on the digital divide in developing countries were excluded. Our intention was to obtain an overview of empirical research on the digital divide in settings that are technologically and economically advanced. To ensure covering the mainstream journals in information research we searched within the basket of eight [11], and additionally, the Communications of the Association for IS (CAIS), Information and Organization and Information Technology \& People. Furthermore, we searched for articles in all Association of Information Systems (AIS) conferences and the Hawaiian International Conference on System Sciences (HICSS). The search yielded 165 unique articles in total. The next step was to read the titles and abstracts of the articles identified checking their relevance to the research question. For this step, the exclusion criteria were used. Specifically, we excluded papers that only casually mentioned the digital divide but had a different focus, literature reviews and conceptual papers and papers focused on developing countries. After this step, 53 papers were shortlisted and used as a basis for a backward and forward search which yielded 9 additional papers. For the backward and forward search, we decided to include papers based on topic relevance only without restrictions for the publication outlet. Finally, the full text of each one of the shortlisted papers was assessed for relevance applying the inclusion-exclusion criteria to the full content. Additionally, the quality of the research reported was assessed. For the quality assessment, each article's method description was checked for rigorousness. After this step, a final corpus of 17 articles was defined (Table 1). Figure 1 provides an overview of the selection process.

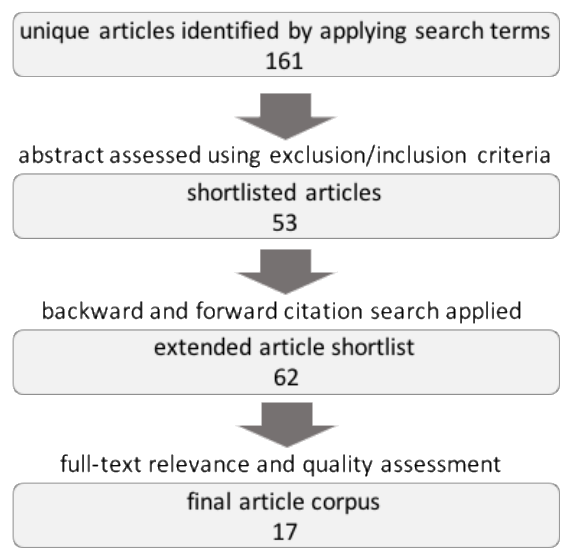

Fig. 1. The literature selection process. 
Table 1. List of selected articles

\begin{tabular}{|c|c|}
\hline \# & Reference \\
\hline 1 & $\begin{array}{l}\text { Abdelfattah, B. M., Bagchi, K., Udo, G., \& Kirs, P. (2010). Understanding the Internet } \\
\text { Digital Divide: An Exploratory Multi-Nation Individual-Level Analysis. Paper presented at } \\
\text { the 16th American Conference on Information Systems (AMCIS 2010). Proceedings. } \\
\text { Paper 542. }\end{array}$ \\
\hline 2 & $\begin{array}{l}\text { Niehaves, B., \& Plattfaut, R. (2010). The Age-Divide in Private Internet Usage: A } \\
\text { Quantitative Study of Technology Acceptance. Paper presented at the } 16^{\text {th }} \text { American } \\
\text { Conference on Information Systems (AMCIS 2010). Proceedings. Paper } 407 \text {. }\end{array}$ \\
\hline
\end{tabular}

3 Hsieh, J. P.-A., Rai, A., \& Keil, M. (2011). Addressing digital inequality for the socioeconomically disadvantaged through government initiatives: Forms of capital that affect ICT utilization. Information Systems Research, 22(2), 233-253.

4 Wei, K.K., Teo, H.H., Chan, H. C., \& Tan, B. C. (2011). Conceptualizing and testing a social cognitive model of the digital divide. Information Systems Research, 22(1), 170187.

5 Chang, S.-I., Yen, D. C., Chang, I.-C., \& Chou, J.-C. (2012). Study of the digital divide evaluation model for government agencies-a Taiwanese local government's perspective. Information Systems Frontiers, 14(3), 693-709.

6 Ghobadi, S., \& Ghobadi, Z. (2015). How access gaps interact and shape digital divide: a cognitive investigation. Behaviour \& Information Technology, 34(4), 330-340.

7 Niehaves, B., \& Plattfaut, R. (2014). Internet adoption by the elderly: employing IS technology acceptance theories for understanding the age-related digital divide. European Journal of Information Systems, 23(6), 708-726.

8 Friemel, T. N. (2016). The digital divide has grown old: Determinants of a digital divide among seniors. New media \& society, 18(2), 313-331.

9 Alam, K., \& Imran, S. (2015). The digital divide and social inclusion among refugee migrants: A case in regional Australia. Information Technology \& People, 28(2), 344-365.

10 Racherla, P., \& Mandviwalla, M. (2013). Moving from access to use of the information infrastructure: A multilevel sociotechnical framework. Information Systems Research, 24(3), 709-730.

11 Ebermann, C., Piccinini, E., Brauer, B., Busse, S., \& Kolbe, L. (2016). The Impact of Gamification-Induced Emotions on In-car IS Adoption - The Difference between Digital Natives and Digital Immigrants. Paper presented in the $49^{\text {th }}$ Hawaii International Conference on System Sciences (HICSS 2016) (pp. 1338-1347). IEEE.

12 Fox, G., \& Connolly, R. (2018). Mobile health technology adoption across generations: Narrowing the digital divide. Information Systems Journal, 28(6), 995-1019.

13 Chipeva, P., Cruz-Jesus, F., Oliveira, T., \& Irani, Z. (2018). Digital divide at individual level: Evidence for Eastern and Western European countries. Government Information Quarterly, 35(3), 460-479.

14 Quan-Haase, A., Williams, C., Kicevski, M., Elueze, I., \& Wellman, B. (2018). Dividing the grey divide: Deconstructing myths about older adults' online activities, skills, and attitudes. American Behavioral Scientist, 62(9), 1207-1228.

15 Szeles, M. R. (2018). New insights from a multilevel approach to the regional digital divide in the European Union. Telecommunications Policy, 42(6), 452-463.

16 Reisdorf, B. C., \& Rikard, R. V. (2018). Digital rehabilitation: a model of reentry into the digital age. American Behavioral Scientist, 62(9), 1273-1290.

17 de Carvalho, C. V., Olivares, P. C., Roa, J. M., Wanka, A., \& Kolland, F. (2018). Digital Information Access for Ageing Persons. Paper presented at the 18th International Conference on Advanced Learning Technologies (ICALT 2018) (pp. 345-347). IEEE. 


\section{Results}

This section presents the literature review results. Recurring digital divide factors are identified and presented for the different population groups threatened by digital inequality. Furthermore, measures for addressing the challenge of the digital divide are described and organized in three key intervention domains. The key findings of the literature review are summarized in the concept matrix which is presented in Table 2. A comprehensive overview of all the papers reviewed is included in Appendix 1.

\subsection{Factors contributing to the Digital Divide}

In settings with advanced infrastructures and economy, physical access is not a key source of digital inequalities anymore and the studies that examine issues of unequal access show that this gap is closing (with the exception of special population groups such as prisoners). Nevertheless, there is still a stark difference between access and acceptance. Several of the studies reviewed combine established technology acceptance theories and models with concepts related to the characteristics and preferences of individuals and pragmatic constraints related to access. Going beyond socioeconomic demographics, a number of personal contributing factors were identified: a) motivation, b) personality traits (e.g. openness, extraversion, conscientiousness), c) digital skills. Many of the studies reviewed focus on particular groups of people. Specifically, a significant part of the literature is focused on the elderly who are also referred to as "digital immigrants" (as opposed to digital natives that have been interacting with digital technology since childhood). Additionally, several studies are focused on specific marginalized population groups such as prisoners and refugees. In the paragraphs that follow, we present the research findings organizing them according to the different groups studied.

Elderly Population. Although digital technologies have been around for several decades, some of the elderly members of society have difficulties learning about and adopting digital tools and services. Hence, targeted efforts are needed for fully integrating senior citizens in the knowledge society [12]. This is not a physical access problem because, for the senior citizens that do not own computers or mobile devices, access is provided in libraries and community centers. This group has problems with the actual use of digital technologies [13]. Elderly people may want to stay connected and learn new digital skills, but at the same time, they tend to feel overwhelmed [14]. Still, they do engage in a wide range of online activities despite having limited skills, and some are eager to learn as they go [14]. Unwillingness to adopt digital technologies by the elderly was found to stem from mistrust, high-risk perceptions, and desire for privacy [15]. Research also shows that not all seniors have the same stances towards digital technologies [14]. Overall older people are a heterogeneous group, and it is important not to overlook their differences (for instance in digital skills and use of social media). Niehaves and Plattfaut [16] used the unified theory of acceptance and use of technology (UTAUT) and the model of adoption of technology in households (MATH) to explain internet acceptance and usage by the elderly. These models were able to predict how the elderly could be encouraged to learn to use technology. Performance 
expectancy (ease of use) was found to be the main driver for internet usage among senior citizens.

Marginalised Population Groups. Language barriers as for instance, in the case of refugees, can cause social exclusion and may hinder the process of ICT assimilation throughout society. Alam and colleagues found in their research that even though refugees and immigrants in the US are motivated to learn about new technology, many were not able to do so for three main reasons: unaffordable cost, language barriers and lack of skills [17]. They showed that refugees think that technology is helpful for finding new jobs or facilitating social engagement but barriers such as expenses and problems with access prevent them from using the Internet [17]. Reisdorf and Rikard (2018) focus on the challenges of paroles that are released from prison and argue that very little research on the digital divide focuses on complete nonusers, bringing into attention the problems that paroles encounter on release from prison after lengthy periods of nonuse [18]. They propose a model of digital rehabilitation that addresses both online and offline arenas in the rehabilitation of prisoners. The model fills a gap in prisoner rehabilitation that usually only targets offline arenas and issues, while the digital realm is often disregarded [18].

General Population. In the general population, socioeconomic factors including educational level relate to the digital inequalities [19]. A study conducted by Chipeva, Cruz-Jesus, Oliveira, and Irani [20] combined the extended unified theory of acceptance and use of technology (UTAUT2) with the big five personality traits (openness, extraversion, agreeableness, conscientiousness, and neuroticism) to investigate factors that relate to the digital divide. The study is interesting because it goes beyond the sociodemographic characteristics of individuals showing the influence of attitudes and personality traits. Additionally, the study showed the impact of cultural differences by identifying factors that differ across Bulgarian and Portuguese cultures. Performance expectancy and habit turned out to be the strongest predictors of ICT acceptance, also, the personality characteristics of openness, extraversion, and agreeableness were found to be significant predictors of ICT acceptance [20]. Unreasonably high expectation and specific personality traits are found to have a negative impact on ICT acceptance [21] while individual characteristics such as gender, language, race, household and area of residence (rural or urban) do not seem to have an impact [22]. Nevertheless, Hsieh and colleagues suggest that demographic factors such as ethnic background and education that have been shown to explain the high acceptance of ICT can also explain the nonuse of ICT [23]. Socio-economically disadvantaged people are affected by digital inequalities. Two individuals might have equal access to digital technologies, but a difference in skills can create digital inequalities [24]. Abdelfattah argues that socioeconomic status among groups can cause inequality and some groups may be disadvantaged because they are too far embedded in older systems, which makes it difficult for them to adopt newer ICTs [25]. 
Table 2. Concept Matrix

\begin{tabular}{|c|c|c|c|c|c|c|c|c|c|c|c|c|c|c|c|c|c|}
\hline & \multicolumn{17}{|c|}{ Papers Reviewed } \\
\hline & 1 & 2 & 3 & 4 & 5 & 6 & 7 & 8 & 9 & 10 & 11 & 12 & 13 & 14 & 15 & 16 & 17 \\
\hline \multicolumn{18}{|c|}{ Type of Inequality } \\
\hline $\begin{array}{l}\text { ICT } \\
\text { access }\end{array}$ & $\mathrm{x}$ & $\mathrm{x}$ & $\mathrm{x}$ & $\mathrm{x}$ & $\mathrm{x}$ & $\mathrm{x}$ & $\mathrm{x}$ & $\mathrm{x}$ & $\mathrm{x}$ & $\mathrm{x}$ & & & & & & $\mathrm{x}$ & \\
\hline $\begin{array}{l}\text { ICT } \\
\text { acceptance }\end{array}$ & $\mathrm{x}$ & $\mathrm{x}$ & $\mathrm{x}$ & $\mathrm{x}$ & $\mathrm{x}$ & $\mathrm{x}$ & $\mathrm{x}$ & $\mathrm{x}$ & $\mathrm{x}$ & $\mathrm{x}$ & $\mathrm{x}$ & $\mathrm{x}$ & $\mathrm{x}$ & $\mathrm{x}$ & & & \\
\hline \multicolumn{18}{|c|}{ Digital Divide Contributing Factors } \\
\hline Motivation & & $\mathrm{x}$ & $\mathrm{x}$ & & & $\mathrm{x}$ & $\mathrm{x}$ & $\mathrm{x}$ & & & $\mathrm{x}$ & & $\mathrm{x}$ & $\mathrm{x}$ & & & \\
\hline $\begin{array}{l}\text { Personality } \\
\text { Traits }\end{array}$ & & & & & & $\mathrm{x}$ & & & & $\mathrm{x}$ & & & $\mathrm{x}$ & $\mathrm{x}$ & & & \\
\hline $\begin{array}{l}\text { Digital } \\
\text { Skills }\end{array}$ & $\mathrm{x}$ & $\mathrm{x}$ & & $\mathrm{x}$ & $\mathrm{x}$ & $\mathrm{x}$ & $\mathrm{x}$ & $\mathrm{x}$ & $\mathrm{x}$ & & & $\mathrm{x}$ & & $\mathrm{x}$ & $\mathrm{x}$ & $\mathrm{x}$ & $\mathrm{x}$ \\
\hline \multicolumn{18}{|c|}{ Digital Divide Remedies } \\
\hline $\begin{array}{l}\text { Policy } \\
\text { Measures }\end{array}$ & & $\mathrm{x}$ & $\mathrm{x}$ & $\mathrm{x}$ & $\mathrm{x}$ & $\mathrm{x}$ & $\mathrm{x}$ & & $\mathrm{x}$ & $\mathrm{x}$ & & & $\mathrm{x}$ & & $\mathrm{x}$ & & \\
\hline $\begin{array}{l}\text { Education/ } \\
\text { Training }\end{array}$ & & & & & $\mathrm{x}$ & $\mathrm{x}$ & $\mathrm{x}$ & & & $\mathrm{x}$ & & $\mathrm{x}$ & & & $\mathrm{x}$ & $\mathrm{x}$ & $\mathrm{x}$ \\
\hline $\begin{array}{l}\text { Design } \\
\text { Tailoring }\end{array}$ & & & & & & & & & $\mathrm{x}$ & & $\mathrm{x}$ & $\mathrm{x}$ & $\mathrm{x}$ & $\mathrm{x}$ & & & \\
\hline
\end{tabular}

\subsection{Overcoming the Digital Divide}

Policy-making is considered instrumental for closing the digital gap [20]. Szeles (2018) suggests a mix of regional and national policy measures to bridge the digital gap in EU countries [19]. These measures include: stimulating regional economic growth, strengthening tertiary education, increasing R\&D expenditure, discouraging early leaving from education. Effective evaluation mechanisms make it easier to develop new policies in the public sector and can contribute to addressing the digital divide [26]. This makes it possible for policy-makers to take action by implementing various initiatives to bridge the divide among certain sectors of society, such as elderly people and socio-economically disadvantaged groups [23]. Policies that leverage existing communities, social structures, and local actors can help in reducing digital inequalities [27]. Such policies can stimulate public/private partnerships with grassroots organizations that already have "hooks" in local communities. Policy measures should allow room for local adaptations, as contextual and local elements seem to play a role for technology users and could influence policy success [27].

Van Dijk suggests that proper training and education might help mitigate the inequalities of the digital divide [3]. Furthermore, information campaigns also have a significant role to play. The digital divide can be narrowed if vendors engage in trust building campaigns targeting the elderly [15]. In addition, social networks, friends and family are important for supporting the training of disadvantaged people in technologies. Digital literacy programs targeting senior citizens can help them develop the necessary skills and abilities to use digital mobile devices so that they could be part of the Digital Society [12, 15]. Friemel's study [28], conducted in Switzerland, finds that internet usage among the elderly was encouraged by family members and friends 
and that a private learning setting was more effective and was preferred over a professional learning approach. Overall, prior research has shown that senior citizens appreciate very much digital literacy programs and have positive perceptions of the digital abilities they develop [12]. Looking at the specific marginalized population group of prisoners, Reisdorf and Rikard (2018) also point to the importance of training and call for more research on digital skills development and interventions to mitigate digital exclusion experienced during imprisonment.

Chipeva and colleagues [20] address the concrete level of conceptualizing and developing ICT solutions and point to the importance of taking into account individual differences for creating proper stimuli to different user groups. This makes the role of appropriate design for overcoming the digital divide a center of attention. Their findings show that it is important to emphasize ICT usefulness and performance rather than ease of use as performance expectancy is the strongest antecedent of behavioral intention while effort expectancy does not have the same strong role. Similarly, Quan-Haase and colleagues emphasize the need for tools and applications to be specifically developed to support the elderly in their current activities [14] as opposed to tools that are not related to their everyday practices. Overall, research points to the importance of functionalities that suit the needs of specific user groups to stimulate ICT acceptance.

\section{Discussion and Implications for Future Research}

Prior research shows that the digital divide is related to socioeconomic characteristics and also personality traits, motivation and digital skills. Digital inequalities in the technologically and economically advanced societies have shifted from unequal physical access to inequalities in actual usage. Although the physical access divide seems to be closing, inequalities in use persist. Measures for crossing the divide range include policy interventions, training and design. The findings of this review can be a foundation for further research orienting researchers within the domain. Several questions remain unanswered related to the digital divide in our societies thus further studies are needed. Several future research topics were suggested by the authors of the papers reviewed. Further work should be undertaken to investigate different national, social and cultural settings [13, 20, 24] across geographical contexts [16]. Future research should pay attention to how institutional and environmental factors at the macro level may influence individuals' ability and motivation to access and use technology [27]. Furthermore, further research is needed to extend established models with new variables. Future investigations may add variables to social theories [16, 22 , 23, 28], personal traits models [20, 21], and capital theory [23]. Future research should consider testing other psychological variables [13] and socio-economical aspects [18, 23 ] to develop a more fine-grained understanding of the association between digital divide variables and ICT acceptance [15, 16, 20, 23]. Additionally, further work is required to research the effect of interventions to avoid the exclusion of citizens from the digital realm addressing inequalities [17, 18, 24]. 


\section{Conclusion}

Remaining cautious of digital inequalities is critical in our digitalization era. These inequalities are manifested not just in terms of access issues but also, in terms of what citizens can actually do with digital technologies. Understanding how digital inequalities emerge and finding ways to address them, needs to be a key premise for the development of e-societies. Researchers largely agree that the digital divide should be defined in terms that go beyond accessibility to access and actual use and that a personality model can help us to understand acceptance and use of technology complementing models related to economic and social resources. Such a personality model can include personality traits (e.g. openness, extraversion, conscientiousness) and also, motivation, and digital skills. Concerted action at the policy level, training initiatives and tailored design catering for the most vulnerable user groups can all contribute in closing the gap. The findings of this literature review can provide a foundation for further research development and a basis for researchers to orient themselves within the domain and position their own work.

\section{References}

1. Pick, J. and A. Sarkar, Theories of the digital divide: Critical comparison, in 49th Hawaii International Conference on System Sciences (HICSS). IEEE. p. 3888-3897 (2016).

2. OECD, Understanding the digital divide. Paris, France (2001).

3. Van Dijk, J., The evolution of the digital divide: The digital divide turns to inequality of skills and usage. Digital enlightenment yearbook. 2012: p. 57-75 (2012).

4. DiMaggio, P., Hargiattai, E., Celeste, C., and Shafer, S. Digital inequality: From unequal access to differentiated use, in Social inequality. 2004, Russell Sage Foundation. p. 355400 (2004).

5. Van Dijk, J.A., Digital divide research, achievements and shortcomings. Poetics, 34(4-5): p. 221-235 (2006).

6. Van Deursen, A.J. and E.J. Helsper, The third-level digital divide: Who benefits most from being online?, in Communication and information technologies annual. Emerald Group Publishing Limited. p. 29-52 (2015).

7. Axelsson, K., U. Melin, and I. Lindgren, Public e-services for agency efficiency and citizen benefit-Findings from a stakeholder centered analysis. Government Information Quarterly, 30(1): p. 10-22 (2013).

8. Vassilakopoulou, P., M. Grisot, and M. Aanestad, Enabling Electronic Interactions between Patients and Healthcare Providers: a service design perspective. Scandinavian Journal of Information Systems, 2016. 28(1): p. 71-90.

9. Kitchenham, B., Procedures for performing systematic reviews. Keele University Technical Report, UK, TR/SE-0401(2004): p. 1-26 (2004).

10. Webster, J. and R.T. Watson, Analyzing the past to prepare for the future: Writing a literature review. MIS Quarterly, 26(2): p. xiii-xxiii (2002).

11. AIS. Association for Information Systems. Senior Scholars' Basket of Journals, https://aisnet.org/page/SeniorScholarBasket, last accessed 2019/01/29. 
12. Carvalho , C.V.d., et al., Digital Information Access for Ageing Persons, in 18th International Conference on Advanced Learning Technologies (ICALT 2018). IEEE, p. 345-347 (2018).

13. Niehaves, B. and R. Plattfaut, The Age-Divide in Private Internet Usage: A Quantitative Study of Technology Acceptance, in the 16th American Conference on Information Systems (AMCIS 2010). Proceedings. Paper 407. Americas Conference on Information Systems Proceedings. Paper 407 (2010).

14. Quan-Haase, A., et al., Dividing the Grey Divide: Deconstructing Myths About Older Adults' Online Activities, Skills, and Attitudes. American Behavioural Scientist, 62(9): p. 1207-1228 (2018)

15. Fox, G. and R. Connolly, Mobile health technology adoption across generations: Narrowing the digital divide. Information Systems Journal, 28(6): p. 995-1019 (2018).

16. Niehaves, B. and R. Plattfaut, Internet adoption by the elderly: employing IS technology acceptance theories for understanding the age-related digital divide. European Journal of Information Systems, 23(6): p. 708-726 (2014).

17. Alam, K. and S. Imran, The digital divide and social inclusion among refugee migrants: A case in regional Australia. Information Technology \& People, 28(2): p. 344-365 (2015).

18. Reisdorf, B.C. and R.V. Rikard, Digital Rehabilitation: A model of Reentry into the Digital Age. American Behavioral Scientist, 62(9): p. 1273-1290 (2018).

19. Szeles, M.R., New insights from a multilevel approach to the regional digital divide in the European Union. Telecommunications Policy, 42(6): p. 452-463 (2018).

20. Chipeva, P., et al., Digital divide at individual level: Evidence for Eastern and Western European countries. Government Information Quartely, 35(3): p. 460-479 (2018).

21. Ebermann, C., et al., The Impact of Gamification-Induced Emotions on In-car IS Adoption - The Difference between Digital Natives and Digital Immigrants, in 49th Hawaii International Conference on System Sciences (HICSS 2016). IEEE. p. 1338-1347 (2016).

22. Abdelfattah, B.M., et al., Understanding the Internet Digital Divide: An Exploratory MultiNation Individual-Level Analysis, in 16th American Conference on Information Systems (AMCIS 2010). Proceedings. Paper 542 (2010).

23. Hsieh, J.P.-A., A. Rai, and M. Keil, Addressing digital inequality for the socioeconomically disadvantaged through government initiatives: Forms of capital that affect ICT utilization. Information Systems Research, 22(2): p. 233-253 (2011).

24. Ghobadi, S. and Z. Ghobadi, How access gaps interact and shape digital divide: a cognitive investigation. Behaviour \& Information Technology, 34(4): p. 330-340 (2015).

25. Abdelfattah, B.M., Individual-Multinational Study of Internet Use: The Digital Divide Explained by Displacement Hypothesis and Knowledge-gap Hypothesis, in 18th American Conference on Information Systems (AMCIS 2012). Proceedings. Paper 24 (2012).

26. Chang, S.-I., et al., Study of the digital divide evaluation model for government agenciesa Taiwanese local government's perspective. Information Systems Frontiers, 14(3): p. 693709 (2012).

27. Racherla, P. and M. Mandviwalla, Moving from access to use of the information infrastructure: A multilevel sociotechnical framework. Information Systems Research, 24(3): p. 709-730 (2013).

28. Friemel, T.N., The digital divide has grown old: Determinants of a digital divide among seniors. New media \& society, 18(2): p. 313-331 (2016). 
Appendix 1. Overview of key elements of the reviewed articles

\begin{tabular}{|c|c|c|c|c|c|}
\hline \# & Author(s) & Year & Research objectives & Findings & Future research directions \\
\hline 1 & $\begin{array}{l}\text { Abdelfattah } \\
\text { el al. }\end{array}$ & 2010 & $\begin{array}{l}\text { Aims to identify factors of the digital divide } \\
\text { that separate the digitally deprived from } \\
\text { frequent internet users. The study covers } \\
\text { both developed and developing nations. }\end{array}$ & $\begin{array}{l}\text { Socio-economics, demographic variables, use of media } \\
\text { channels, and religion (to some extent) influence the } \\
\text { digital divide; most factors differ between the digitally } \\
\text { deprived and frequent users of the Internet. }\end{array}$ & $\begin{array}{l}\text { More research on the influences of self-perceptions, } \\
\text { traditional media, religion, and word-of-mouth on the digital } \\
\text { divide; additional research on the factors that contribute to } \\
\text { the digital divide extremes. }\end{array}$ \\
\hline 3 & Hsieh et al. & 2011 & $\begin{array}{l}\text { Aims to understand the inequality between } \\
\text { the socio-economically disadvantaged and } \\
\text { the socio-economically advantaged to inform } \\
\text { public policy; uses capital theory as a } \\
\text { theoretical lens. }\end{array}$ & $\begin{array}{l}\text { The disadvantaged realized greater gains in cultural } \\
\text { capital, social capital and habitus than the advantaged; } \\
\text { intention to use ICT was influenced by intrinsic and } \\
\text { extrinsic motivations for habitus and self-efficacy of } \\
\text { cultural capital but not by social capital }\end{array}$ & $\begin{array}{l}\text { Research on how the socio-economically disadvantaged can } \\
\text { effectively convert their ICT usage into economic, health, } \\
\text { social and educational benefits; extend the capital framework } \\
\text { with economic capital (e.g., affordability of training and } \\
\text { infrastructure); utilize and extend social theories. }\end{array}$ \\
\hline 4 & Wei et al. & 2011 & $\begin{array}{l}\text { Examines digital inequalities among students } \\
\text { as: digital access divide, digital capability } \\
\text { divide (capability to exploit IT), and digital } \\
\text { outcome divide (learning and productivity). }\end{array}$ & $\begin{array}{l}\text { Generates insights into the relationships between the } \\
\text { three levels of the divide; provides an account of the } \\
\text { effects of the digital divide }\end{array}$ & $\begin{array}{l}\text { Understand other effects of the digital divide and how } \\
\text { governments can use interventions to avoid citizen exclusion } \\
\text { from the digital realm }\end{array}$ \\
\hline 5 & $\begin{array}{l}\text { Chang \& } \\
\text { Yen }\end{array}$ & 2012 & $\begin{array}{l}\text { Aims to identify the digital divide and } \\
\text { measure its different levels among local } \\
\text { governments in Taiwan }\end{array}$ & $\begin{array}{l}\text { A model of five dimensions was developed to enable } \\
\text { local government assess pros and cons of digitalization; } \\
\text { the model addresses government agencies }\end{array}$ & $\begin{array}{l}\text { Use the model as a point of departure for studies on other } \\
\text { countries or city governments in Taiwan; identify new } \\
\text { dimensions for customizing the model. }\end{array}$ \\
\hline 6 & $\begin{array}{l}\text { Ghobadi \& } \\
\text { Ghobadi }\end{array}$ & 2015 & $\begin{array}{l}\text { Focuses on inequalities in ICT access and in } \\
\text { particular on motivational, material, skill, } \\
\text { and usage gaps; demonstrates interactions } \\
\text { and linkages between these gaps }\end{array}$ & $\begin{array}{l}\text { Provides a theoretical model which includes } 22 \\
\text { concepts and the linkages between them; contributes } \\
\text { insights about dynamics shaping the digital divide and } \\
\text { develops new concepts related to gaps. }\end{array}$ & $\begin{array}{l}\text { Use the theoretical model for future research on the digital } \\
\text { divide; conduct studies on the digital divide in different } \\
\text { cultures that develop interventions to reduce the digital divide }\end{array}$ \\
\hline 7 & $\begin{array}{l}\text { Niehaves \& } \\
\text { Plattfaut }\end{array}$ & 2014 & $\begin{array}{l}\text { Focuses on the age-related digital divide; } \\
\text { identifies important influencing factors } \\
\text { regarding internet usage }\end{array}$ & $\begin{array}{l}\text { Combines the UTAUT model and MATH with socio- } \\
\text { demographical variables to explain the variance of } \\
\text { internet adoption among the elderly. }\end{array}$ & $\begin{array}{l}\text { Conduct research on other geographical settings; repeat the } \\
\text { research with larger sample size; conduct studies on e- } \\
\text { inclusion to explore and theorize social context. }\end{array}$ \\
\hline 8 & Friemel & 2016 & $\begin{array}{l}\text { Focuses on internet usage among the elderly, } \\
\text { the so-called "gray divide" (seniors } 65+\text { ) }\end{array}$ & $\begin{array}{l}\text { Old seniors }(70+) \text { are partially excluded, gender } \\
\text { differences found to disappear; family encouragement } \\
\text { found to have a strong influence on internet usage. }\end{array}$ & $\begin{array}{l}\text { Investigate the influence of social networks; conduct social } \\
\text { network analysis to reveal new concepts for analyzing the } \\
\text { digital divide among seniors. }\end{array}$ \\
\hline 9 & $\begin{array}{l}\text { Alam \& } \\
\text { Imram }\end{array}$ & 2015 & $\begin{array}{l}\text { Examines the factors that influence refugee } \\
\text { adoption of digital technology and its } \\
\text { relevance to their social inclusion in } \\
\text { Australia. }\end{array}$ & $\begin{array}{l}\text { A digital divide exists among refugee groups related to } \\
\text { inequalities in physical access to and use of digital } \\
\text { technology, the skills necessary to use technologies } \\
\text { effectively and the ability to pay for services }\end{array}$ & $\begin{array}{l}\text { Investigate how education, period of stay and gender } \\
\text { influence the digital divide among refugee groups; Examine } \\
\text { whether this digital divide is unique to the region under study } \\
\text { or applies to wider Australian society }\end{array}$ \\
\hline
\end{tabular}




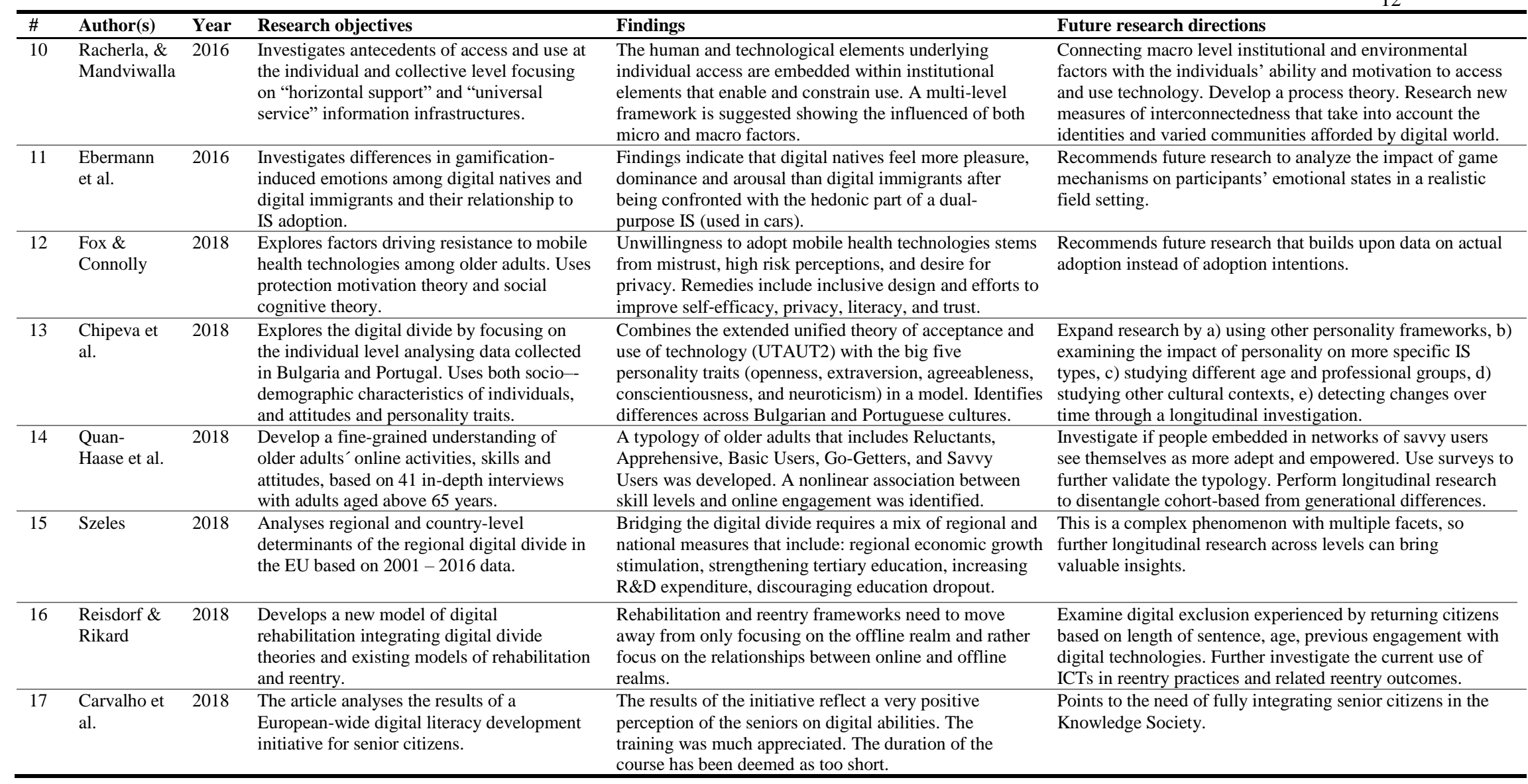

